\title{
Diabetes Ameliorating Effect of Mushrooms
}

\author{
Mohammad Azizur Rahman*, Rabeya Akter \\ Department of Biochemistry and Molecular Biology, Jahangirnagar University, Savar, Dhaka, Bangladesh.
}

*Corresponding author: Mohammad Azizur Rahman, Department of Biochemistry and Molecular Biology, Jahangirnagar University, Savar, Dhaka, Bangladesh.

\section{Received Date: 28 September 2021 | Accepted Date: 21 October 2021 | Published Date: 29 October 2021}

Citation: Mohammad A Rahman, R Akter. (2021). Diabetes Ameliorating Effect of Mushrooms. Biomedical Research and Clinical Reviews. 5(1); DOI: $10.31579 / 2692-9406 / 086$

Copyright: (C) 2021 Mohammad Azizur Rahman, This is an open-access article distributed under the terms of the Creative Commons Attribution License, which permits unrestricted use, distribution, and reproduction in any medium, provided the original author and source are credited.

\begin{abstract}
The growing impact of type 2 diabetes in the majority of the population requires the introduction of better and more secure treatments, but also requires the development of new prevention strategies to reduce the incidence and prevalence of the disease. Significantly, type 2 diabetes is an important preventable disease and can be prevented or delayed by lifestyle intervention. Edible and medicinal macrofungi, mushrooms have been reported having diabetes ameliorating effects. Current study reviews the potentiality of both edible and medicinal mushrooms in preventing and ameliorating the diabetic complications as well as the future aspects of mushrooms against this metabolic disorder.
\end{abstract}

Keywords: diabetes mellitus; mushrooms; insulin; hyperglycemia; metabolic disorder

\section{Introduction}

Diabetes mellitus is a life-threatening chronic metabolic disease caused by lack of insulin and/or insulin dysfunction characterized by hyperglycemia [1]. Over 220 million people worldwide suffer from diabetes and its complications, and this number is predicted to increase in future years [1]. Diabetes is a chronic disease that occurs when the pancreas is no longer able to make insulin, or when the body cannot make good use of the insulin it produces [1]. Insulin is a hormone made by the pancreas that acts like a key to let glucose from the food we eat pass from the blood stream into the cells in the body to produce energy [1]. All carbohydrate foods are broken down into glucose in the blood. Insulin helps glucose get into the cells [1]. There are three main types of diabetes - type 1, type 2 and gestational [2]. Type 1 diabetes can develop at any age, but occurs most frequently in children and adolescents [2]. When one have type 1 diabetes, body produces very little or no insulin, which means that one need daily insulin injections to maintain blood glucose levels under control [2]. Type 2 diabetes is more common in adults and accounts for around $90 \%$ of all diabetes cases [3]. When one have type 2 diabetes, body does not make good use of the insulin that it produces [3]. The cornerstone of type 2 diabetes treatment is healthy lifestyle, including increased physical activity and healthy diet [3]. However, over time most people with type 2 diabetes will require oral drugs and/or insulin to keep their blood glucose levels under control. Gestational diabetes (GDM) is a type of diabetes that consists of high blood glucose during pregnancy and is associated with complications to both mother and child [3]. GDM usually disappears after pregnancy but women affected and their children are at increased risk of developing type 2 diabetes later in life [3]. Diabetes dramatically increases risk of various cardiovascular problems, including coronary artery disease with chest pain (angina), heart attack, stroke, narrowing of the arteries (atherosclerosis) and high blood pressure. Nerve damage (neuropathy) [3].

Diabetes mellitus is a life-threatening chronic metabolic disease caused by lack of insulin and/or insulin dysfunction characterized by hyperglycemia. Over 220 million people worldwide suffer from diabetes and its complications, and this number is predicted to increase in future years [1-3]. The growing impact of type 2 diabetes in the majority of the population requires the introduction of better and more secure treatments, but also requires the development of new prevention strategies to reduce the incidence and prevalence of the disease. Significantly, type 2 diabetes is an important preventable disease and can be prevented or delayed by lifestyle intervention.

Many studies have been published on the efficacy of new preventive treatments for diabetes or its complications; however, there is still little information on its applicability. Medicinal mushrooms present an exciting opportunity for the development of new types of therapeutics and have been valued for their potential healing properties for centuries. Mushrooms have been valued as remedies for disease and as natural health foods for thousands of years, and they are incredibly popular foods in numerous countries through-out the world. Biologically active metabolites and components derived from medicinal mushrooms have been demonstrated to have controlling effects on diabetes through the regulation of several pathophysiological pathways related to the onset of diabetes. Some of the anti-hyperglycemic mechanisms of medicinal mushrooms have been investigated including $\beta$-cell improvement and insulin releasing activity, antioxidant defences, carbohydrate metabolism pathways, $\alpha$-glucosidase and aldose reductase inhibitory activities. 


\section{Mushrooms as a functional food mediator in preventing and ameliorating diabetes:}

Mushroom has ameliorating effects on diabetes [4]. Beta-D glucan is a form of soluble dietary fiber that has been strongly linked to improving cholesterol and boosting heart health [4]. It can also help our body regulate blood sugar, reducing the risk of type 2 diabetes [5]. Oyster (Pleurotus) and shiitake (Lentinula) mushrooms are believed to have the most effective beta glucans [5]. Some mushrooms appear to be effective for both the control of blood glucose and the modification of the course of diabetic complications without side-effects [5].

Numerous species of mushrooms exist in nature; however, only a few are used as edibles. Many Asian countries use traditionally wild edible mushrooms as delicious and nutritional foods and medicine. Wild edible mushrooms are appreciated not only for their texture and flavor but also for the chemical and nutritional characteristics. Edible mushrooms have higher protein contents and minerals and contain less fat but are rich in B vitamins, vitamin $\mathrm{D}$, vitamin $\mathrm{K}$ and sometimes vitamins $\mathrm{A}$ and $\mathrm{C}[6]$.

Mushrooms are not only sources of nutrients but also have been reported as therapeutic foods, useful in preventing diseases such as hypertension, diabetes, hypercholesterolemia and cancer [7]. These functional characteristics are mainly due to the presence of dietary fiber and in particular chitin and beta glucans [7]. Certain mushrooms species have antitumor, antiviral, antithrombotic and immunomodulating properties [8-9]. Therefore it is useful to carry out more research on mushrooms with a view to identify active principles in them for the treatment of diabetes mellitus and its complications.

\section{Medicinal mushrooms and diabetes:}

\section{Tremella fuciformis (berk)}

Tremella fuciformis has been given the common names snow fungus or silver ear fungus [10]. In Chinese cuisine, T. fuciformis is traditionally used in sweet dishes [10]. Despite its tasteless nature, T. fuciformis is valued for its gelatinous texture as well as its supposed medicinal benefits. Glucuronoxylomannan (AC) from the fruiting bodies of $T$. fuciformis exhibited a significant dose-dependent hypoglycemic activity in normal mice and also showed a significant activity in streptozotocin-induced diabetic mice, by intraperitoneal administration [10]. The anti-diabetic activities of the exopolysaccharides (EPS) produced by submerged mycelial culture of $T$. fuciformis in ob/ob mice were investigated [11]. The results suggested that EPS exhibited considerable hypoglycemic effect and improved insulin sensitivity possibly through regulating PPAR-gamma-mediated lipid metabolism [11]. These results indicated that $T$. fuciformis has potential oral hypoglycemic effect as a functional food for the management of DM [10-11].

\section{Wolfiporia extensa (Peck) Ginns (formerly known as Poriacocos)}

Poriacocos, a rotten pine-tree fungus is a wood decay fungus but has a terrestrial growth habit [12]. It has long been used as traditional Chinese medicine and food [12]. Poriacocos, alone or in combination with other herbs is often used to treat diabetes as well as other disorders [12]. Mechanistic study on streptozocin (STZ) treated mice showed that the crude extract, dehydrotumulosic acid, dehydrotrametenolic acid, and pachymic acid of Poriacocos exhibited different levels of insulin sensitizer activity [12-13]. The data suggested that the Poriacocos extract and its triterpenes reduce postprandial blood glucose levels in $\mathrm{db} / \mathrm{db}$ mice via enhanced insulin sensitivity irrespective of PPAR- $\gamma$ [12-13].

\section{Ganoderma lucidum (Curtis)}

Ganoderma lucidum has been use since the 4th century A.D. and is well known in China as the herb of longevity. Ganoderma is to be famous tonic and found an important place in Chinese medicine due to its beneficial effects to all viscera and nontoxic nature [14-17]. Research workers have found that $G$. lucidum polysaccharides (GL-PS) dose-dependently lowered the serum glucose levels after administration in mice. G. lucidum polysaccharides (GL-PS) possess the hypoglycemic effect on normal mice; one mechanism is through its insulin releasing activity due to a facilitation of $\mathrm{Ca}^{2+}$ inflow to the pancreatic beta cells [18].

\section{Ganoderma applanatum (Pers.) Pat. andCollybiaconfluens} (Pers.: Fr.)

The hypoglycemic effects of Ganodermaapplanatumexo-polymer (GAE) and Collybiaconfluensexo polymer (CCE) produced by submerged mycelial cultures in streptozotocin (STZ)-induced diabetic rats were shown hypoglycemic effects [19]. The results strongly demonstrated the potential of GAE and CCE in combating diabetes in experimental animals [19].

\section{Auricularia auricula-judae (Bull.)}

Auricularia auricula-judae, known as the Jew's Ear, Jelly Ear is a species of edible Auriculariales mushroom found worldwide. Distinguished by its noticeably ear-like shape and brown coloration, it grows upon wood. It is popular in China, where the medicinal use of food is common; a soup containing A. auricula-judae, chicken, pakchoi and ginger is used medicinally for dealing with colds and fevers by reducing the heat of the body. The hypoglycemic effect of water-soluble polysaccharide from fruiting bodies of A. auricula-judae was investigated on genetically diabetic mice (KK-Ay) [19-20]. This study showed that FA had a hypoglycemic effect on KK-Ay mice, and the reduced food consumption was not a major factor which contributed to the hypoglycemic action of -soluble polysaccharide from fruiting bodies of A. auricula-judae [19-20].

\section{Agaricus campestris}

Agaricus campestris has fast maturing and short shelf-life. A. campestris has been documented as a traditional treatment for diabetes. Its insulinlike and insulin releasing activities have been reported [21]. The administration of mushroom in the diet and drinking water countered the hyperglycaemia of streptozotocin-diabetic mice [21].

\section{Agaricus subrufescens (Peck)}

Agaricus subrufescens is a choice edible, with a somewhat sweet taste and fragrance of almonds. In Japan, A. subrufescens is also the most popular complementary and alternative medicine used by cancer patients [22]. $A$. brasiliensis fruit body is useful as a health promoting food. Performed studies on murine models and human volunteers to examine the immuneenhancing effects of the naturally outdoor-cultivated fruit body of $A$. brasiliensis KA21 (i.e. Agaricusblazei) has shown antitumor, leukocyte-enhancing, hepatopathy-alleviating and endotoxin shockalleviating effects in mice [23-25]. In the human study, percentage body fat, percentage visceral fat, blood cholesterol level and blood glucose level were decreased and natural killer cell activity was increased. Beta-glucans and oligosaccharides (AO) of Agaricus blazei Murill showed anti-hyperglycemic, anti-hypertriglyceridemic, antihypercholesterolemic, and anti-arteriosclerotic activity indicating overall anti-diabetic activity in diabetic rats, AO had about twice the activity of beta-glucans with respect to anti-diabetic activity [23-25]. Further supplement of A. blazei Murill extract has improved insulin resistance among subjects with type 2 DM [23-25]. The increase in adiponectin concentration after taking A. blazei Murill extract might be the mechanism that brings the beneficial effect [23-25].

\section{Inonotus obliquus}

Chaga mushroom (Inonotus obliquus), a white rot fungus, belongs to the hymenochaetaceae family of Basidomycetes. Chaga mushroom grows on 
birch trees in colder northern climates. Since the sixteenth century, Chaga has been used as a folk medicine in Russia and western Siberia [26-27]. Researches exposed that the dry matter of culture broth of I. obliquus possesses significant anti-hyperglycemic, anti-lipid peroxidative and antioxidant effects in alloxan-induced diabetic mice [26-27].

\section{Hericium erinaceus (Bull.)}

Hericium erinaceus is named for its shape, and is literally interpreted as monkey head mushrooml in China. Recent studies have determined that many types of mushroom (egHericiumspp), may have important physiological functions in humans, including antioxidant activities, the regulation of blood lipid levels and reduction of blood glucose levels [28-29]. Researchers have found that the hypoglycemic effects of feeding the methanol extract of H. erinaceus to streptozotocin-induced diabetic rats were significantly lower elevation rates of blood glucose levels [28-29].

\section{Agrocybe aegerita}

It is an important valuable source possessing varieties of bioactive secondary metabolites such as indole derivatives with free radical scavenging activity, cylindan with anticancer activity, and also agrocybenine with antifungal activity [30]. A glucan and a heteroglycan were isolated from a hot-water extract of the fruiting bodies of A. cylindracea [30]. A glucan showed a remarkable hypoglycemic activity in both normal and streptozotocin-induced diabetic mice by intraperitoneal administration, and its activity was higher than that of heteroglycan [30].

\section{Coprinus comatus (O.F.Mull)}

The young mushrooms of Coprinus comatus, before the gills start to turn black, are edible. It can sometimes be used in mushroom soup with parasol mushroom . This species is cultivated in China as food. When young it is an excellent edible mushroom provided that it is eaten soon after being collected. It can be used as a hypoglycemic food or medicine for hyperglycemic people. The hypoglycemic activity of fermented mushroom, $C$. comatus tested on Alloxan and adrenalin-induced hyperglycemic mice [31-33]. It confirmed that $C$. comatus rich in vanadium has significant anti-hyperglycemic effect [31-33].

\section{Cordyceps sinensis}

Cordycepssinensis, known in English commonly as caterpillar fungus is considered a medicinal mushroom in traditional Chinese medicine. Crude polysaccharides of $C$. sinensis were tested in normal mice and streptozotocin-induced diabetic mice. It significantly lowered the glucose level by oral administration in mice [34-35]. A polysaccharide obtained from the cultural mycelium of Cordycepssinensis showed potent hypoglycemic activity in genetic diabetic mice after intraperitoneal administration, and the plasma glucose level was quickly reduced in normal and streptozotocin-induced diabetic mice after intravenous administration [34-35]. The diabetic rats had significantly lower weight gain and higher blood glucose response in oral glucose tolerance test than the control rats; and these changes were significantly reduced by administrating the fruiting body of Cordyceps and these improvements suggested that fruiting body of Cordyceps has a potential to be the functional food for diabetes [36]. Another research revealed that isolated polysaccharide from $C$. sinensis, named CSP-1 produced a significant drop in blood glucose level in both STZ-induced diabetic rats and alloxan-induced diabetic mice [36]. It suggested that CSP-1 may stimulate pancreatic release of insulin and/or reduce insulin metabolism.

\section{Grifola frondosa (Dicks.)}

Grifola frondosa is also very popular in Korea, China and Japan, where it is cultivated as maitake, the dancing mushroom. Controlled experiments have found many beneficial activities attributable to $G$. frondosa and/or its extracts. The reason Maitake lowers blood sugar is due to the fact that the mushroom naturally contains an alphaglucosidase inhibitor [37-38]. Alpha-glucosidase inhibitory activities were found in aqueous methanol extracts of the seeds of Momordica charantia and the fruit bodies of $G$. frondosa. Researchers evaluated the anti-diabetic effect of an alpha-glucan (MT-alpha-glucan) from the fruit body of G. frondosa on KK-Ay mice [39]. These data suggest that MT-alpha-glucan has an anti-diabetic effect on KK-Ay mice, which might be related to its effect on insulin receptors (i. increasing insulin sensitivity and ameliorating insulin resistance of peripheral target tissues). Further animal and human experiments also proven that anti-diabetic activity present in the fruit body of G. frondosa [40].

\section{Conclusion}

Many studies have been published on the efficacy of new preventive treatments for diabetes or its complications; however, there is still little information on its applicability. Medicinal mushrooms present an exciting opportunity for the development of new types of therapeutics and have been valued for their potential healing properties for centuries. Mushrooms have been valued as remedies for disease and as natural health foods for thousands of years, and they are incredibly popular foods in numerous countries through-out the world. Biologically active metabolites and components derived from medicinal mushrooms have been demonstrated to have controlling effects on diabetes through the regulation of several pathophysiological pathways related to the onset of diabetes. Some of the anti-hyperglycemic mechanisms of medicinal mushrooms have been investigated including $\beta$-cell improvement and insulin releasing activity, antioxidant defences, carbohydrate metabolism pathways, $\alpha$-glucosidase and aldose reductase inhibitory activities. Thus, mushrooms could be a potential therapeutic agent against diabetes mellitus.

\section{Acknowledgement}

Authors gratefully acknowledge the grant-in-aid provided by Jahangirnagar University, Bangladesh and University Grants Commission of Bangladesh and National Science and Technology Fellowship provided by the Government of Bangladesh.

\section{References}

1. American Diabetes Association. (2011). Diagnosis and classification of diabetes mellitus. Diabetes Care. 34(S1):6269.

2. Kerner W, Brückel J; German Diabetes Association. (2014). Definition, classification and diagnosis of diabetes mellitus. Exp Clin Endocrinol Diabetes. 122(7):384-386.

3. Khursheed R, Singh SK, Wadhwa S, Kapoor B, Gulati M, Kumar R, Ramanunny AK, Awasthi A, Dua K. (2019). Treatment strategies against diabetes: Success so far and challenges ahead. Eur J Pharmacol.

4. Dubey SK, Chaturvedi VK, Mishra D, Bajpeyee A, Tiwari A, Singh MP. (2019). Role of edible mushroom as a potent therapeutics for the diabetes and obesity. 3 Biotech. 9(12):450.

5. Lindequist U, Haertel B. (2020). Medicinal Mushrooms for Treatment of Type 2 Diabetes: An Update on Clinical Trials. Int J Med Mushrooms. 22(9):845-854.

6. Rahman, M. A., Abdullah, N. Aminudin, N. (2015). Interpretation of Mushroom as a common therapeutic agent for Alzheimer's disease and cardiovascular diseases. Critical Reviews in Biotechnology.

7. Yahaya, N.F.M, Rahman, M. A., Abdullah, N. (2014). Therapeutic potential of mushrooms in preventing and ameliorating hypertension. Trends in Food Science and Technology. 39(2):104-115. 
8. Rahman, M. A., Abdullah, N. Aminudin, N. (2015). Interpretation of Mushroom as a common therapeutic agent for Alzheimer's disease and cardiovascular diseases. Critical Reviews in Biotechnology.

9. Rahman, M. A., Abdullah, N., Aminudin, N. (2017). Corroborative Assessment of Mushroom as the Graceful Ageing and Lifespan Promoting. Biointerface Research in Applied Chemistry. 7(3):1-13.

10. Cho EJ, Hwang HJ, Kim SW, Oh JY, Baek YM, Choi JW, Bae SH, Yun JW. (2007). Hypoglycemic effects of exopolysaccharides produced by mycelial cultures of two different mushrooms Tremella fuciformis and Phellinus baumii in ob/ob mice. Appl Microbiol Biotechnol.

11. Wu T, Xu B. (2015) Antidiabetic and antioxidant activities of eight medicinal mushroom species from China. Int $\mathrm{J}$ Med Mushrooms. 17(2):129-140.

12. Kim JH, Sim HA, Jung DY, Lim EY, Kim YT, Kim BJ, Jung MH. (2019). Poria cocus Wolf Extract Ameliorates Hepatic Steatosis through Regulation of Lipid Metabolism, Inhibition of ER Stress, and Activation of Autophagy via AMPK Activation. Int J Mol Sci. 20(19):4801.

13. Li X, Ma L, Zhang L. (2019). Molecular basis for Poria cocos mushroom polysaccharide used as an antitumor drug in China. Prog Mol Biol Transl Sci. 163:263-296.

14. Rahman M A, Abdullah N, Aminudin N (2017). Corroborative assessment of mushroom as the graceful ageing and lifespan promoting agent. Biointerface Research in Applied Chemistry. $7: 3: 1-13$.

15. Rahman, M. A., Abdullah, N., Aminudin, N. (2017). Ganoderma lucidum (P.) Karst Modulates Memory and Learning Related Behaviour in Alzheimer's diseased Rats. Behavioural Brain Research.

16. Rahman, M.A., Abdullah, N., Aminudin, N. Ganoderma lucidum (P.). (2017). Karst Ameliorates Alzheimer's diseased Rat Brain Proteomics. Journal of Proteome Research.

17. Rahman, M. A., Abdullah, N., Aminudin, N. (2017). Antioxidative and Hypocholesterolemic potentiality of the solvent partitioned fractions of Ganoderma lucidum (Curtis) P. Karst (lingzhi mushroom). International Journal of Medicinal Mushrooms.

18. Chen M, Xiao D, Liu W, Song Y, Zou B, Li L, Li P, Cai Y, Liu D, Liao Q, Xie Z. (2020). Intake of Ganoderma lucidum polysaccharides reverses the disturbed gut microbiota and metabolism in type 2 diabetic rats. Int $\mathrm{J}$ Biol Macromol. 155:890-902.

19. Wińska K, Mączka W, Gabryelska K, Grabarczyk M. (1998). Mushrooms of the Genus Ganoderma Used to Treat Diabetes and Insulin Resistance. Molecules. 2019 Nov 11;24(22):4075. doi: 10.3390/m Yuan Z, He P, Cui J, Takeuchi H. Hypoglycemic effect of water-soluble polysaccharide from Auricularia auricula-judae Quel. on genetically diabetic KK-Ay mice. Biosci Biotechnol Biochem. 62(10):1898-903.

20. Yuan Z, He P, Cui J, Takeuchi H. (1998). Hypoglycemic effect of water-soluble polysaccharide from Auricularia auriculajudae Quel. on genetically diabetic KK-Ay mice. Biosci Biotechnol Biochem. 62(10):1898-903.

21. Gray AM, Flatt PR. (1998). Insulin-releasing and insulin-like activity of Agaricus campestris (mushroom). J Endocrinol. 157(2):259-266.

22. Wisitrassameewong K, Karunarathna SC, Thongklang N, Zhao R, Callac P, Moukha S, Férandon C, Chukeatirote E, Hyde KD. (2012). Agaricus subrufescens: A review. Saudi J Biol Sci. 19(2):131-146.
23. Yamanaka D, Liu Y, Motoi M, Ohno N. (2013). Royal sun medicinal mushroom, Agaricus brasiliensis Ka21 (higher Basidiomycetes), as a functional food in humans. Int $\mathrm{J}$ Med Mushrooms. 15(4):335-343.

24. Souza E Silva L, Dos Santos RC, Silva ME, Pedrosa ML. (2017). Agaricus brasiliensis (sun mushroom) affects the expression of genes related to cholesterol homeostasis. Eur $\mathbf{J}$ Nutr. 56(4):1707-1717.

25. Yamamoto Y, Tsuru Y, Motoi M, Amano S. (2014). Agaricus brasiliensis KA21 improves circulatory functions in spontaneously hypertensive rats. J Med Food. 17(3):295-301.

26. Xu HY, Sun JE, Lu ZM, Zhang XM, Dou WF, Xu ZH. (2010). Beneficial effects of the ethanol extract from the dry matter of a culture broth of Inonotus obliquus in submerged culture on the antioxidant defence system and regeneration of pancreatic beta-cells in experimental diabetes in mice. Nat Prod Res. 24(6):542-53.

27. Van der Bijl P. (2019). The pharmacological potential and possible molecular mechanisms of action of Inonotus obliquus from preclinical studies. Phytother Res. 33(8):1966-1980.

28. Liang B, Guo Z, Xie F, Zhao A. (2013). Antihyperglycemic and antihyperlipidemic activities of aqueous extract of Hericium erinaceus in experimental diabetic rats. BMC Complement Altern Med. 13:253.

29. Zhang C, Li J, Hu C, Wang J, Zhang J, Ren Z, Song X, Jia L. (2017). Antihyperglycaemic and organic protective effects on pancreas, liver and kidney by polysaccharides from Hericium erinaceus SG-02 in streptozotocin-induced diabetic mice. Sci Rep. 7(1):10847.

30. Zhang Z, He L, Hu S, Wang Y, Lai Q, Yang P, Yu Q, Zhang S, Xiong F, Simsekyilmaz S, Ning Q, Li J, Zhang D, Zhang H, Xiang X, Zhou Z, Sun H, Wang CY. (2015). AAL exacerbates pro-inflammatory response in macrophages by regulating Mincle/Syk/Card9 signaling along with the Nlrp3 inflammasome assembly. Am Transl Res. 7(10):1812-1825.

31. Gao Z, Kong D, Cai W, Zhang J, Jia L. (2021). Characterization and anti-diabetic nephropathic ability of mycelium polysaccharides from Coprinus comatus. Carbohydr Polym. 251:117081.

32. Zhou S, Liu Y, Yang Y, Tang Q, Zhang J. (2015). Hypoglycemic Activity of Polysaccharide from Fruiting Bodies of the Shaggy Ink Cap Medicinal Mushroom, Coprinus comatus (Higher Basidiomycetes), on Mice Induced by Alloxan and Its Potential Mechanism. Int J Med Mushrooms. 17(10):957-964.

33. Lv Y, Han L, Yuan C, Guo J. (2009). Comparison of hypoglycemic activity of trace elements absorbed in fermented mushroom of Coprinus comatus. Biol Trace Elem Res. 131(2):177-185.

34. El Zahraa Z El Ashry F, Mahmoud MF, El Maraghy NN, Ahmed AF. (2012). Effect of Cordyceps sinensis and taurine either alone or in combination on streptozotocin induced diabetes. Food Chem Toxicol. 50(3-4):1159-1165.

35. Cao C, Yang S, Zhou Z. (2020). The potential application of Cordyceps in metabolic-related disorders. Phytother Res. 34(2):295-305.

36. Luo Y, Yang SK, Zhou X, Wang M, Tang D, Liu FY, Sun L, Xiao L. (2015). Use of Ophiocordyceps sinensis (syn. Cordyceps sinensis) combined with angiotensin-converting enzyme inhibitors (ACEI)/angiotensin receptor blockers (ARB) versus $\mathrm{ACEI} / \mathrm{ARB}$ alone in the treatment of diabetic kidney disease: a meta-analysis. Ren Fail. 37(4):614-34.

37. Lindequist U, Haertel B. (2020). Medicinal Mushrooms for Treatment of Type 2 Diabetes: An Update on Clinical Trials. Int J Med Mushrooms. 22(9):845-854. 
38. He Y, Zhang L, Wang H. (2019). The biological activities of the antitumor drug Grifola frondosa polysaccharide. Prog Mol Biol Transl Sci. 163:221-261.

39. Guo WL, Shi FF, Li L, Xu JX, Chen M, Wu L, Hong JL, Qian M, Bai WD, Liu B, Zhang YY, Ni L, Rao PF, Lv XC. (2019). Preparation of a novel Grifola frondosa polysaccharidechromium (III) complex and its hypoglycemic and hypolipidemic activities in high fat diet and streptozotocininduced diabetic mice. Int J Biol Macromol. 131:81-88.

40. Jiang T, Wang L, Ma A, Wu Y, Wu Q, Wu Q, Lu J, Zhong T. (2020). The hypoglycemic and renal protective effects of Grifola frondosa polysaccharides in early diabetic nephropathy. J Food Biochem. 44(12):13515.
This work is licensed under Creative Commons Attribution 4.0 License

\section{To Submit Your Article Click Here: Submit Manuscript}

DOI: $10.31579 / 2692-9406 / 086$
Ready to submit your research? Choose Auctores and benefit from:

$>$ fast, convenient online submission

$>$ rigorous peer review by experienced research in your field

$>$ rapid publication on acceptance

$>$ authors retain copyrights

$>$ unique DOI for all articles

$>$ immediate, unrestricted online access

At Auctores, research is always in progress.

Learn more auctoresonline.org/journals/biomedical-research-andclinical-reviews- 